\title{
Strongyloides stercoralis; REPORTE DE UN CASO EN EL POST-TRASPLANTE RENAL
}

\author{
JAVIER AMAYA NIETO ${ }^{*}$, FERNANDO GIRÓN LUQUE ${ }^{2}$, YENNY BAEZ SUAREZ ${ }^{3}$
}

${ }^{1} \mathrm{MD}$, Colombiana de Trasplantes, Bogotá, Colombia. Grupo de Investigación Colombiana de Trasplantes.

${ }^{2}$ Cirujano de Trasplantes, Bogotá, Colombia. Grupo de Investigación Colombiana de Trasplantes. Lider del Grupo de Investigación Colombiana de Trasplantes.

${ }^{3}$ Cirujana de Trasplantes, Bogotá, Colombia. Grupo de Investigación Colombiana de Trasplantes.

${ }^{1}$ Correspondencia: Javier Antonio Amaya.

jamaya@colombianadetrasplantes.com

DIRECCIÓN POSTAL: CALLE 61 NO 13-23 OF 402. COLOMBIANA DE TRASPLANTES.

Recibido: 6 Diciembre 2016 Aceptado: 3 Febrero 2017

\section{RESUMEN}

La hiperinfección por Strongyloides spp (HS) es una enfermedad rara dentro de la población inmunocompetente, pero puede presentarse en pacientes inmunocomprometidos como los pacientes trasplantados renales por lo que al realizar un análisis de la literatura actual acerca del tema se hace importante. En el presente artículo presentamos el caso clínico de un paciente trasplantado renal que después de iniciar la terapia inmunosupresora, presenta síntomas y signos de HS, diagnosticado y tratado de forma exitosa.

Palabras claves: Trasplante de riñón; Strongiloidiasis; Inmunosupresión; Insuficiencia renal 


\title{
Strongyloides stercoralis;
}

\section{REPORT OF A CASE ON THE RENAL POSTPLASPLANT}

\begin{abstract}
Hyperinfection strongyloidiasis is a pretty uncommon disease within immunocompetent individuals but it can affect immunosuppressed patients like post renal transplantation and that is because it is important to review the literature about it. In this article, we will write about the case report of a transplanted patient who developed hyperinfection strongyloidiasis after started the Immunosuppressive Therapy. This patient was diagnosed and treated successfully.
\end{abstract}

Keywords: Kidney transplantation, Strongyloidiasis, Immunosuppression, Renal insufficiency

\section{Strongyloides stercoralis; \\ RELATO DO CASO EM PÓS-TRANSPLANTE RENAL}

\section{RESUMO}

Hiperinfecção a forteoidilidíase é uma doença bastante incomum em indivíduos imunocompetentes, mas pode afetar pacientes imunossuprimidos, como transplante pós-renal, e é porque é importante revisar a literatura sobre isso. Neste artigo, iremos escrever sobre o relato de caso de um paciente transplantado que desenvolveu hiperinfecção da solidioclíase após o início da terapia imunossupressora. Este paciente foi diagnosticado e tratado com êxito.

Palavras-chave: Transplante de rim; Strongyloidiasis; Imunossupressão; renal insufficiency. 


\section{Introducción}

La estrongiloidiasis es una infección producida por el nematodo Strongyloides stercoralis; que afecta una población estimada entre 100 y 200 millones de personas a nivel mundial $(1,2)$. El parasito se encuentra en la tierra especialmente en áreas tropicales y subtropicales del globo, sin embargo, se han reportado casos en países como Australia, Japón y Estados Unidos de Norte América (3). Este parasito es de importancia por su alta prevalencia en la población general de zonas endémicas, como las mencionadas, en las que se han encontrado porcentajes que varian entre el $1 \%$ y el $75 \%$. En Colombia se ha reportado una prevalencia entre un 16 a un $19 \%(1,3)$.

Dentro del espectro de presentaciones clínicas producidas por este nematodo, encontramos la HS, la estrongioloidiasis diseminada y la forma crónica. En lo que respecta a este artículo, es necesario entender que en la HS las larvas están confinadas en localizaciones propias del ciclo parasitario (intestino, pulmones y piel), característica que se presenta también en la forma crónica. Sin embargo, en la HS los signos y síntomas son mucho más graves que en la forma crónica. Por otro lado, en la estrongiloidiasis diseminada las larvas se pueden encontrar presentes en otros órganos como el sistema nervioso central, el tracto urinario y el hígado. $(1,2,4)$

Este parasito tiene dos características que le han permitido sobrevivir a lo largo del tiempo de forma eficiente, en primer lugar, puede completar su ciclo de vida fuera de un huésped, a temperaturas húmedas y cálidas de la tierra; $y$ en segundo lugar que pueden causar infecciones asintomáticas crónicas en huéspedes inmunocompetentes $(2,3,5)$. Teniendo en cuenta lo anterior, enfocamos esta revisión a los pacientes inmunosuprimidos especialmente aquellos que se encuentran bajo regímenes de medicamentos post-trasplante, pues en este tipo de pacientes el compromiso inmunológico predispone a estos individuos a presentar HS y estrongiloidiasis diseminada, las cuales modifican críticamente los posibles desenlaces (6).

En primera instancia el parasito alcanza la piel que penetra buscando la circulación sanguínea, para terminar, alojándose en los alveolos pulmonares que rompe para ascender por la vía respiratoria y ser deglutido hasta el intestino delgado en donde cavita la pared intestinal y deposita sus huevos; después de esto el parasito es expulsado vía heces y en los casos que logra cruzar la piel de la región perianal y llegar a la circulación de nuevo, se completa la "autoinfección" que ha demostrado ocurrir más en paciente comprometidos inmunológicamente y a su vez causar más "infecciones diseminadas" así como Hiperinfecciones. Estas hiperinfecciones han demostrado una mortalidad hasta del $87 \%$, por lo que definitivamente la enfermedad tiene importancia clínica $(5,6,7)$

La Hiperinfección por Strongyloides spp. Es la razón principal por la que en algunos han propuesto que tanto el donante como el receptor deben ser tamizados buscando este parasito $e$ incluso han propuesto tratamiento empírico teniendo en cuenta las zonas endémicas, debido a la gravedad de la presentación clínica que involucra más frecuentemente el intestino delgado y los pulmones $(7,8,9)$. Dentro de los posibles desenlaces encontramos cuadros graves de desnutrición severa, alteraciones hidroelectrolíticas, trastornos neurológicos y del sistema respiratorio, así como casos de fallo del injerto a los pocos meses después del trasplante e incluso la muerte $(8,9)$.

Como motivo adicional de discusión, debemos tener en cuenta que el trasplante renal ha sido el tipo de trasplante que más frecuentemente se asocia a HS (10). A continuación, presentamos un paciente que desarrolló una HS posterior al trasplante renal y al manejo inmunosupresor, mostrando hallazgos histológicos, endoscópicos y paraclínicos.

\section{Reporte de caso}

Hombre de 49 años procedente de Bogotá con antecedente de enfermedad renal crónica estadío cinco secundaria a riñones poliquísticos e hipertensión arterial crónica (HTA) en diálisis desde el 2009, a quien se le realiza trasplante renal heterotópico de donante cadavérico el cual se lleva a cabo sin complicaciones quirúrgicas. Como agente de inducción fue usado Basiliximab. La terapia de mantenimiento se realizó con Tacrolimus $4 \mathrm{mg} /$ día, Micofenolato sódico $2 \mathrm{gr} /$ día y libre de esteroides.

Al mes del trasplante el paciente es llevado a biopsia renal por disminución subóptima de azoados, la cual es reportada como negativa para rechazo agudo, pero muestra signos de toxicidad por anticalcineurinicos por lo que se ajusta la dosis de Tacrolimus.

Al tercer mes post-operatorio el paciente presenta un cuadro de astenia, adinamia, hiporexia, vómito, diarrea sin moco sin sangre y fiebre por lo que asiste a urgencias donde se hospitaliza por diagnósticos de hiponatremia, deshidratación y estudio etiológico de la diarrea. Dos días después de hospitalizado el paciente presenta como 
sintoma adicional cefalea de intensidad moderada-severa por lo que se decide realizar Tomografía axial computarizada (TAC) de cráneo simple la cual se encuentra dentro de límites normales y cultivo de líquido céfalo raquídeo (LCR) el cual fue reportado negativo. Adicionalmente, al paciente se le realizan hemocultivo y urocultivo reportados negativos y un coproscópico reportado como normal. Todo lo anterior asociado a los resultados del análisis del LCR sugirieron un diagnóstico de neuroinfección de origen desconocido, posiblemente por Listeria spp. y se inicia antibiótico empírico con Ceftriaxone, Vancomicina y Ampicilina. Después de 16 días de tratamiento el paciente es dado de alta por mejoría de la sintomatología.

Un mes después el paciente es readmitido en el hospital por vomito persistente, se realiza una endoscopia de vías digestivas altas (EDVA) donde se encuentra liquido gástrico y restos fecalóides. Adicionalmente se encuentra persistencia de hiponatremia, cefalea y una proteína $\mathrm{C}$ reactiva (PCR) de $99 \mathrm{mg} / \mathrm{dl}$ por lo que se considera que el paciente cursa con una meningitis sub-tratada y se realiza nueva punción lumbar que muestra niveles normales de proteínas y glucosa con neutrófilos del $100 \%$ por lo que se realizan cultivo para micobacterias y ADA en LCR. Adicionalmente se inicia tratamiento con Cefepime, Vancomicina y Ampicilina, de acuerdo a los protocolos de neuroinfección del Hospital. Ocho días después de hospitalizado, el paciente presenta hematemesis y melenas por lo que se ordena nueva EDVA.

La EDVA realizada 11 días después de la hospitalización muestra las siguientes imágenes

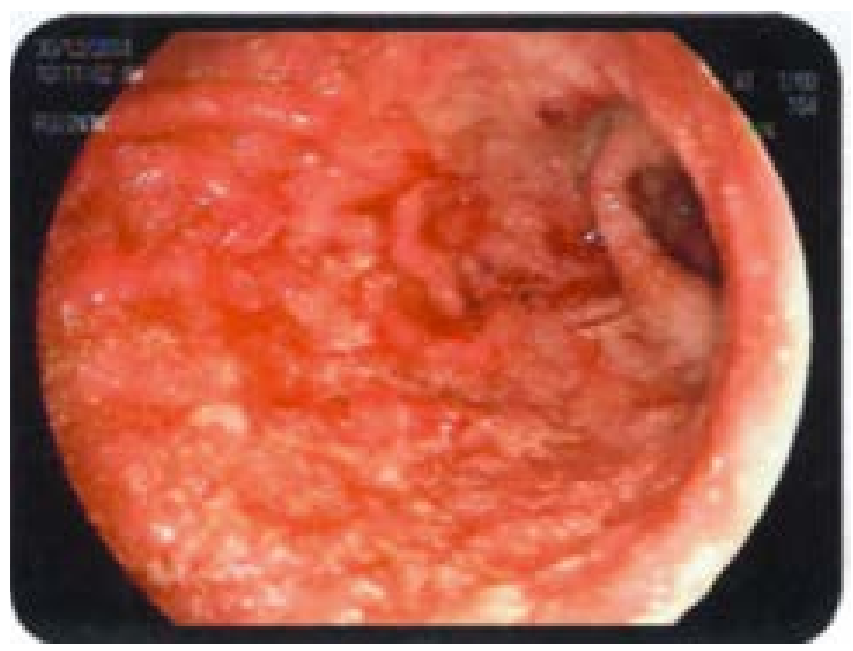

Imagen 1. EDVA. Cavidad gástrica con eritema plano difuso en parches, mucosa con pérdida del patrón vascular.

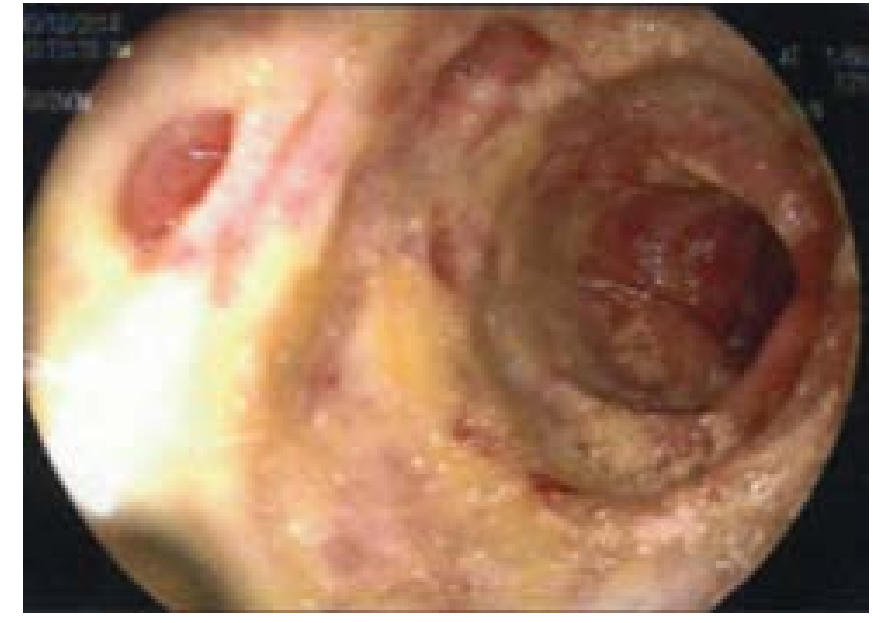

Imagen 2. Duodeno. Bulbo y segunda porción con abundante material fibrinoide adherido, erosiones, ulceraciones y cavitaciones extensas. Perdida de la vascularidad. Se realizan biopsias.

Por hallazgos en la EDVA, se considera que son altamente sugestivos de gastro- duodenitis por Strongyloides spp los cuales son confirmados por el reporte de las biopsias de estómago y duodeno (imagen 3); como paso siguiente, se inició tratamiento con Ivermectina
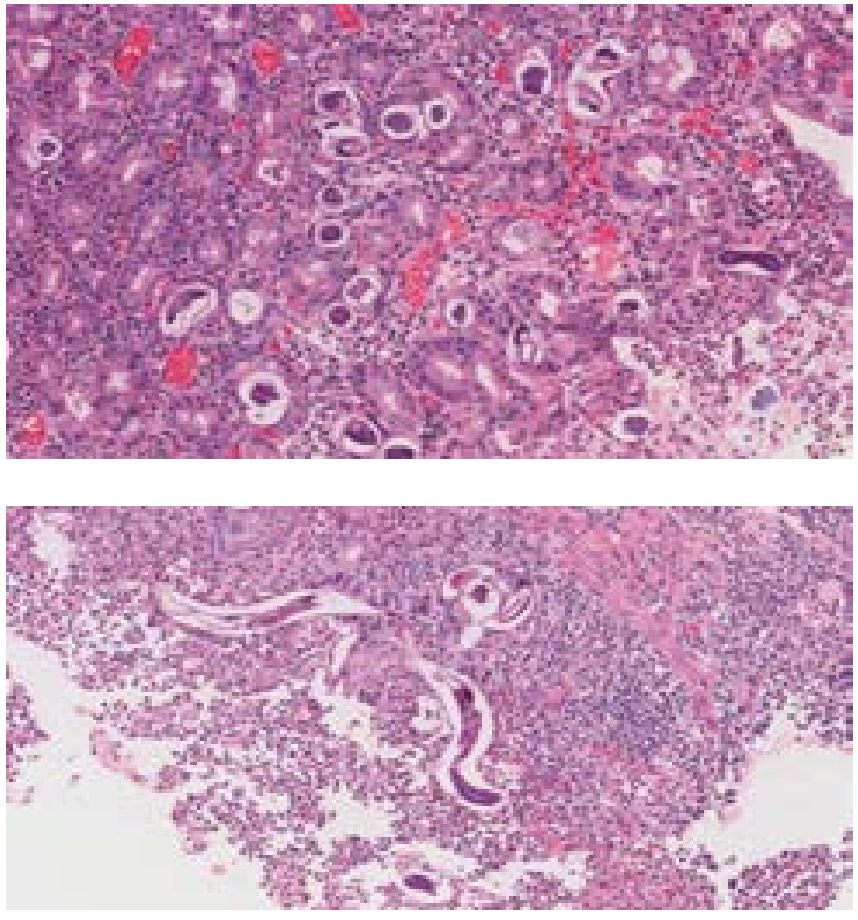

Imagen 3. Biopsia de duodeno. a) Muestra múltiples larvas rabditoides de Strongyloides spp dentro de criptas duodenales. b) Se observa un adulto del parasito cortado sagitalmente. Estrongiolidiasis severa y duodenitis secundaria. 
Posterior a esto se confirma el diagnostico de HS sin afectación de otros órganos. El diagnóstico de HS es soportado por los hallazgos histológicos asociado al cuadro clínico enteropático severo. El paciente evoluciona satisfactoriamente después de completar las dosis de Ivermectina y la terapia simultánea con Albendazol. Finalmente, después de la recuperación nutricional y clínica, el paciente es dado de alta 30 días después de la hospitalización con creatinina de $1.07 \mathrm{mg} / \mathrm{dl}$ la cual se mantuvo por debajo de $1.2 \mathrm{mg} / \mathrm{dl}$ durante el proceso de diagnóstico y tratamiento. Posterior al egreso, el paciente evolucionó satisfactoriamente.

\section{Discusión}

La estrongiloidiasis ha sido reportada como la segunda causa de infección de origen parasitario en el paciente trasplantado renal, después de la toxoplasmosis, por lo que cada vez cobra más importancia el estudio específico de este nematodo tanto en el donante como en el receptor $(8,11)$. Es importante resaltar dos aspectos; desde lo mejor de nuestro conocimiento este es el primer caso reportado en Colombia de hiperinfección por Strongyloides spp en un paciente trasplantado renal, por otro lado como se ha observado en otras publicaciones, identificar si la infección provenía del receptor o del donante es más complicado; en nuestro caso hay dos motivos que podrían indicar que la infección provenía del receptor y son que él siempre ha vivido en zona endémica y segundo que el receptor del otro riñón, no ha presentado ninguna sintomatología similar hasta el momento $(11,12)$.

Uno de los puntos más relevantes del análisis del caso y que creemos que abre la puerta a una discusión, es la evaluación de los pacientes de alto riesgo. Esta discusión es importante porque debido a que nuestro país es área endémica para el parasito, podría considerarse evaluar a receptores y donantes en la medida de lo posible; incluso es posible pensar en profilaxis en el receptor. Todo lo anterior esta soportado en la alta mortalidad que presenta esta enfermedad, que llega al $85 \%$ y a al $100 \%$ en los pacientes en los que se acompaña con bacteriemia $(12,13,4)$. Una razón adicional para considerar el tamizaje en pacientes donantes o receptores de riñón, es que la prevalencia en algunas zonas endémicas puede llegar hasta un $80 \%$. Por las razones anteriores y debido a la falta de consenso acerca de recomendaciones claras en el tema, la sociedad americana de enfermedades infecciosas en trasplantes hizo algunas recomendaciones que vamos a comentar brevemente (14).
Donantes vivos a quienes se les debe realizar tamizaje para Strongyloides spp

1. Donantes que nacieron o vivieron en áreas endémicas, incluyendo militares que hayan estado en estas zonas.

2. Pacientes con eosinofilia inexplicable por otra causa que hayan estado en zonas endémicas.

3. Personas nacidas en E.E.U.U. en contacto con tierra, que vivan en la zona de Appalachia y los estados del suroriente del país.

4. Personas con historia previa de estrongiloidiasis.

Debido a los métodos diagnósticos especializados como lo es la inmufluorescencia para este parasito aún no están disponibles en muchos sitios, se recomienda optar por la serología para Strongyloides spp como un examen paraclínico viable en la mayoría de los sitios, también es posible pensar en exámenes seriados de heces y sospechar siempre que en el cuadro hemático se observe eosinofilia $(14,15)$.

Otro de los puntos importantes a discutir es la forma adecuada en la que se debe realizar el tratamiento, debido a que, en los últimos años, la Ivermectina se ha convertido en el tratamiento de elección para las estrongiloidiasis diseminadas y la HS, demostrando especialmente que, si se utiliza tempranamente, reduce la mortalidad en un $40 \%$. Para el medicamento se ha propuesto y utilizado diferentes esquemas de tratamiento como: $200 \mu \mathrm{gr} / \mathrm{kg} /$ día por 14 días, $200 \mu \mathrm{gr} / \mathrm{kg} /$ dosis cada 48 horas hasta resolución de la sintomatología o $200 \mu \mathrm{gr} / \mathrm{kg} /$ día repitiendo la dosis al día 2,15 y $16(15,16,17)$. Se han propuesto incluso algunos regímenes en los cuales el medicamento es administrado vía subcutánea (18). Esta última conducta no ha mostrado mejores resultados o niveles sanguíneos del medicamento diferentes por lo que no representa diferencia al momento del tratamiento $(16,18)$. Una conducta que ha sido difundida y que es aceptada por la mayoría de los grupos, es que la Ivermectina sea administrada acompañada de Albendazol o Tiobendazol $(15,17,18,19)$.

En el caso del paciente del caso clínico reportado, se utilizó la recomendación de tratamiento con Ivermectina cuatro dosis, en los días cero, dos, quince y dieciséis, tratamiento acompañado con Albendazol. Como medida adicional se realizó tratamiento profiláctico en la esposa por considerarla con alto riesgo; medidas que, asociadas al inicio temprano del medicamento, permitieron que el paciente se recuperará completamente. 


\section{Conflictos de interés}

Los autores declaran no tener de manera directa o indirecta, ningún tipo de conflicto de intereses financieros, académicos o laborales que puedan poner en peligro la validez de este estudio.

\section{Financiación}

El presente trabajo fue financiado internamente por $\mathrm{Co}^{-}$ lombiana de Trasplantes.

\section{Referencias}

1. Organisation WG. World Gastroenterology Organisation. [Online].; 2005 [cited 201610 21. Available from: http://www.worldgastroenterology.org/UserFiles/file/ guidelines/management-of-strongyloidiasis-spanish.pdf.

2. Mehnaaz K. Hyperinfection strongyloidiasis in renal transplant: case report. BMJ. 2014 August; 6(2): p. 1-5.

3. Rivero MJO, Alemán MR, López MC, Moncada L, Harker PR. Detection of Strongyloides stercoralis in Tierralta, Colombia using four parasitological methods. Rev cubana Med trop. 2014; 66(2): p. 202-209.

4. Abdalhamid B, Abadi A, Saghier MA, Joudeh A, Shorman M, Amr S. Strongyloides stercoralis Infection in Kidney Transplant Recipients. Saudi J Kidney Dis Transpl. 2015; 26(1): p. 98-102.

5. Adella RI, Márquez VD. Estrongiloidiasis: epidemiología, manifestaciones clínicas y diagnóstico. Experiencia en una zona endémica: la comarca de La Safor (Valencia). Enferm Infecc Microbiol. 2007; 25(3): p. 38-44.

6. Ferreira CJA, da Silva DA, Almeida PH, Vieira LS, Carvalho VP, Coutinho AF, et al. Fatal disseminated strongyloidiasis after kidney transplantation. Rev Soc Bras Med Trop. 2012 Sept; 45(5): p. 652-654.

7. Le M, Ravin K, Hasan A, Clauss H, Muchant D, JP, et al. Single Donor-Derived Strongyloidiasis in Three Solid Organ Transplant Recipients: Case Series and Review of the Literature. American Journal of Transplantation. 2014 Jan; 14: p. 1199-1206.

8. Katabathina V, Menias C, Pickhardt P, Lubner M, Prasad S. Complications of Immunosuppressive Therapy in Solid Organ Transplantation. Radiol Clin N Am. 2016 March; 54(2): p. 303-319.
9. Len O, Garzoni C, Lumbreras C, Molina I, Meije Y, Pahissa $\mathrm{A}$, et al. Recommendations for screening of donor and recipient prior to solid organ transplantation and to minimize transmission of donor-derived infections. Clin Microbiol Infect. 2014 Jan; 20(7): p. 10-18.

10. Marcos L, Terashima A, DuPont H, Gotuzzo E. Strongyloides hyperinfection syndrome: an emerging global infectious disease. Trans R Soc Trop Med Hyg. 2008 Apr; 102(4): p. 314-8.

11. Roseman D, Kabbani D, Kwah J, Bird D, Ingalls R, Gau$\operatorname{tam} \mathrm{A}$, et al. Strongyloides stercoralis Transmission by Kidney Transplantation in Two Recipients from a Common Donor. Am J Transplant. 2013 September; 13(9): p. 2483-2486.

12. JK, DK, YY, JS, MK. Donor-Derived Strongyloidiasis Infection in Solid Organ Transplant Recipients: A Review and Pooled Analysis. Transplantation Proceedings. 2016; 48: p. 2442-2449.

13. Rivero Z, Salazar S, Villalobos R, Bracho A. Infestación por Strongyloides stercoralis en una paciente inmunosuprimida, hallazgo de hembra adulta en heces. Centro de Análisis de Imágenes Biomédicas. 2008 May; 10(1): p. 1-7.

14. Levi M, Kumar D, Green M, Ison M, Kaul D, Michaels M. Considerations for Screening Live Kidney Donors for Endemic Infections: A Viewpoint on the UNOS Policy. American Journal of Transplantation. 2014 Jan; 14: p. 1003-1011.

15. Pérez F, Núñez F, Martín N, Cabrera R, Rodríguez E. Falla orgánica múltiple por estrongiloidiasis diseminada. Comunicación de un caso. Rev Chilena Infectol. 2012; 29(3): p. 344-347.

16. Fox L. Ivermectin: uses and impact 20 years on. Curr Opin Infect Dis. 2006; 19(1): p. 588-593.

17. JL, EM, JP, PC. Hiperinfección por Strongyloides stercoralis. Med Intensiva. 2010; 34(5): p. 353-356.

18. Bastos E, Oliveira M, Ghazi M, Ferreira F, Mar H. Salvage treatment of disseminated strongyloidiasis in an immunocompromised patient: therapy success with subcutaneous ivermectin. braz j infect dis. 2012; 16(5): p. 479-481.

19. Pocaterra L, Pérez G, Rojas E, Hernán A, Castro J, Goldstein C, et al. Urinary rhabditiform larvae of Strongyloides stercoralis in disseminated disease affecting a kidney-transplanted patient. Rev Med Hered. 2016; 27 : p. 35-40. 